\title{
O PROCESSO DE ENSINAR/APRENDER UMA PERSPECTIVA CRÍTICA EM PSICOLOGIA ESCOLAR E EDUCACIONAL ${ }^{1}$
}

\author{
Fabiana Marques Barbosa Nasciutti ${ }^{2}$ \\ Universidade Estadual de Campinas, Campinas-SP, Brasil \\ Silvia Maria Cintra da Silva \\ Universidade Federal de Uberlândia, Uberlândia-MG, Brasil
}

\begin{abstract}
RESUMO. Em vista das discussões realizadas, desde a década de 1980, acerca de uma concepção crítica em Psicologia Escolar e Educacional, esta investigação buscou compreender como uma supervisora de estágio e uma estagiária em Psicologia de uma instituição de Ensino Superior de Minas Gerais se apropriaram desta concepção crítica. Partindo das contribuições da Psicologia Histórico-Cultural, a escolha metodológica consistiu em conhecer a trajetória de formação das participantes da pesquisa, por meio da modalidade da história oral temática. As participantes fizeram seus depoimentos em sessões de entrevista, totalizando quatro sessões com cada uma, com duração média de quarenta minutos. Mediante as análises, é possível indicar: a mediação do outro como processo inerente às escolhas profissionais e à aprendizagem teórico-prática; os desafios e contradições como parte fundamental do processo de apropriação de uma perspectiva crítica, sugerindo que a aprendizagem é desenvolvida dialeticamente; a atividade prática e os estudos teóricos como componentes indispensáveis para a apropriação conceitual, sendo indicada a necessidade de compreender teoria e prática como uma unidade; o estágio supervisionado como atividade essencial para o aprendizado do futuro psicólogo escolar, indicando a importância da mediação entre a supervisora e a estagiária para a apropriação teórico-prática de uma perspectiva crítica em Psicologia Escolar e Educacional por parte da estagiária, bem como a importância das ações pedagógicas da supervisora neste processo. O estudo aponta a necessidade de mais pesquisas e ações voltadas para a formação do psicólogo escolar em uma perspectiva crítica, a fim de consolidar neste campo práticas contextualizadas e emancipatórias.
\end{abstract}

Palavras-chave: Psicologia Escolar; formação do psicólogo; formação de conceitos.

\section{THE PROCESS OF TEACHING-LEARNING EDUCATIONAL AND SCHOOL PSYCHOLOGY IN A CRITICAL PERPECTIVE}

\begin{abstract}
Through discussions held since the 1980s about Educational and School Psychology in a critical perspective, this research sought to understand the process of appropriation of this concept by a supervisor and an intern psychology of an Institution of Higher Education of Minas Gerais. From the contributions of culturalhistorical psychology, the methodological choice was guided by knowing the professional education trajectory of participants, through investigative modality of oral history. The participants gave their testimonies at interview sessions, totaling four sessions with each, for approximately forty minutes. Upon analysis, it is possible to indicate: the mediation of the other as an inherent process in professional choices and practical theoretical learning; challenges and contradictions as a fundamental part of the appropriation process of a critical perspective, suggesting that learning is developed dialectically; practical activity and theoretical studies as essential components for the conceptual appropriation, the need to understand the theory and practice as a unit is indicated; and finally, the supervised learning as essential to the future school psychologist activity. The internship indicates how the mediation between supervisor and intern was fundamental to the theoretical and practical appropriation of Educational and School Psychology in a critical perspective by the intern, as well as the importance of pedagogical actions of the supervisor. The study points to the need for more research and actions for the school psychologist education in a critical perspective to consolidate this field with contextualized and emancipatory practices.
\end{abstract}

Key words: School psychology; psychologist education; concept formation.

\footnotetext{
1 Apoio e financiamento: Coordenação de Aperfeiçoamento de Pessoal de Nível Superior (CAPES).

2 Endereço para correspondência: Rua Guido Turazza, 195 - Bairro Alto da Bela Vista - CEP 14.600-000 - São Joaquim da Barra-SP.E-mail: fabi.marquesb@hotmail.com
} 


\title{
EL PROCESO DE ENSEÑAR-APRENDER UNA PERSPECTIVA CRÍTICA EN PSICOLOGÍA ESCOLAR Y EDUCACIONAL
}

\begin{abstract}
RESUMEN. En vista de las discusiones realizadas, desde la década de 1980, sobre un enfoque crítico en Psicología Escolar y Educacional, esta investigación buscó comprender el proceso de apropiación de este concepto por una supervisora de prácticas y una aprendiza en prácticas en Psicología de una Institución de Educación Superior en Minas Gerais. A partir de las aportaciones de La Psicología histórico-cultural, la elección metodológica se basó en conocer la trayectoria de la formación de las participantes de la investigación, a través de la modalidad de la historia oral temática. Las participantes concedieron sus relatos en sesiones de entrevistas, habiendo un total de cuatro sesiones con promedio de cuarenta minutos cada. Por medio del análisis, es posible señalar: la mediación del otro como un proceso inherente a las elecciones profesionales y al aprendizaje teóricopráctico; los retos y contradicciones como parte fundamental del proceso de apropiación de una perspectiva crítica, sugiriendo que el aprendizaje se desarrolla dialécticamente; la actividad práctica y los estudios teóricos como componentes indispensables para la apropiación conceptual, lo que indica la necesidad de comprender la teoría y la práctica como una unidad; las prácticas supervisadas como actividad esencial para el aprendizaje del futuro psicólogo escolar, indicando la importancia de la mediación entre supervisora y aprendiza para la apropiación teórico-práctica de una perspectiva crítica en Psicología Escolar y Educacional por parte de la aprendiza, así como la importancia de las acciones pedagógicas de la supervisora en este proceso. El estudio indica la necesidad de más investigaciones y acciones dirigidas para la formación del psicólogo escolar en una perspectiva crítica, para consolidar, en este campo, prácticas contextualizadas y emancipatorias.
\end{abstract}

Palabras-clave: Psicología escolar, formación del psicólogo, formación de concepto.

As práticas individualizantes e descontextualizadas no âmbito da Psicologia Escolar e Educacional começaram a ser questionadas a partir da década de 1980, por um movimento que propõe novos rumos teóricopráticos neste campo. Desde então, as contribuições advindas da perspectiva denominada crítica têm sido fundamentais para um novo direcionamento da área, apresentando uma forma de entendimento acerca do âmbito educacional que busca compreender as raízes históricas e culturais dos fenômenos, a fim de superar posicionamentos teórico-práticos baseados na ideologia capitalista e propor uma atuação socialmente comprometida (Patto, 1984; Tanamachi \& Meira, 2003; Marinho-Araújo \& Almeida, 2008; Souza, 2009; Barbosa \& Souza, 2012; Meira, 2012).

A proposta de uma perspectiva crítica em Psicologia Escolar e Educacional implica, dentre outras necessidades, a de compreender o contexto escolar a partir de um olhar ético e político que entenda como a lógica capitalista afeta as políticas públicas, as relações interpessoais e o cotidiano educacional como um todo. Meira (2012) considera que atualmente a busca por posicionamentos contrários à individualização das questões educacionais já se tornou lugar-comum e que se corre o risco de que isto se reduza a um discurso vazio, sem implicações concretas na realidade. É importante retomar de forma contundente o conceito de crítica, elencando pressupostos teóricos coerentes. Nesse sentido, o pensamento crítico pode se definir pelos seguintes elementos: reflexão a partir de uma lógica dialética, em busca de compreender os fenômenos em sua complexidade; crítica do conhecimento, desvelando os compromissos e interesses ideológicos presentes nas teorias científicas e suas implicações para a realidade; denúncia da degradação, da desigualdade social, da alienação e da exploração de uns pelos outros, indicando que a ciência deve contribuir no processo de transformação social.

Este movimento implica considerar também a formação do psicólogo, pois o modo como este vai atuar no futuro se constitui principalmente durante a graduação. Tendo em vista a importância de pensar em atuações pautadas por uma perspectiva crítica e considerando-se que a formação profissional é um processo voltado para a apropriação teórica e a articulação desta com uma realidade concreta, estamos certamente diante de uma árdua tarefa (Cruces, 2006).

Neste sentido, o estágio supervisionado é uma etapa fundamental para a apropriação teórico-prática de uma profissão (Guzzo, Costa \& Sant'Ana, 2009; Pires, 2011). Configurada principalmente pelo estagiário e pelo supervisor, esta atividade abarca uma relação dialética entre ensino e aprendizagem. Deste modo, entendendo a importância de um 
posicionamento crítico em Psicologia Escolar que sustente a compreensão teórico-prática dos futuros profissionais, o presente artigo decorre de uma pesquisa de mestrado que pretendeu investigar o processo de apropriação de uma perspectiva crítica em Psicologia Escolar e Educacional por uma supervisora e uma estagiária ao longo de suas trajetórias de formação profissional.

Para tanto, parte-se de uma compreensão histórico-cultural da constituição humana, o que significa entender que o homem nasce com funções exclusivamente biológicas e se humaniza no convívio social. Assim, ser capaz de usar a linguagem, o raciocínio lógico, a abstração, o pensamento por conceitos e outras características eminentemente humanas só é possível por meio da apropriação de instrumentos e signos, processo que se dá nas e pelas relações que se estabelecem com o outro (Pino, 2005).

Dentre estas funções psíquicas específicas do ser humano, o pensamento por conceitos científicos tem lugar fundamental no presente estudo, uma vez que o processo de ensinoaprendizagem investigado se refere a um conhecimento profissional. A apropriação de conceitos científicos se dá fundamentalmente pela mediação pedagógica (Vigotski, 2000; Facci, 2004); porém, o mero fato de estar inserido no processo de escolarização não garante que o sujeito aprenda, pois é fundamental considerar a qualidade das atividades pedagógicas e do espaço escolar, bem como o conhecimento do professor acerca do conteúdo e da didática, a disponibilidade e conhecimentos prévios do aluno, além de outros tantos elementos.

Tendo apresentado o norteamento teórico do trabalho, a seguir será discutido o método de pesquisa e feitas as análises decorrentes da investigação.

\section{MÉTODO}

Como a Psicologia Histórico-Cultural propõe o método materialista histórico-dialético de análise, esta investigação inspirou-se nesta concepção para o desenvolvimento do trabalho. A partir das contribuições de Martins (2006), o método materialista histórico-dialético aponta a importância de que os trabalhos investigativos superem a mera descrição e consigam analisar, a partir do aparente, a instância social mais ampla que o circunscreve.

Em termos de escolhas metodológicas, foram entrevistadas uma supervisora e uma estagiária de Psicologia Escolar, vinculadas a uma instituição de Ensino Superior pública de Minas Gerais. Para tanto, foi eleita a modalidade de história oral temática. Segundo Meihy (2002), a história oral consiste na compreensão de diversos elementos sociais a partir de narrativas dos sujeitos que participam ativamente do processo de construção da realidade concreta. É caracterizada por entrevista aberta, na qual o pesquisador vivencia com 0 depoente as narrativas que este tece. A história oral temática é uma modalidade de entrevista aberta que abarca questões norteadoras sobre um assunto específico, de acordo com os objetivos da investigação, sobre as quais o entrevistado discorre livremente.

Ao todo, foram realizadas quatro sessões de entrevista com cada uma das participantes, com duração média de 40 minutos. Os depoimentos foram audiogravados e transcritos na íntegra. A primeira sessão de ambas iniciou-se com a seguinte questão: "Como você foi aprendendo ao longo de sua trajetória os conceitos teóricos da Psicologia Escolar e Educacional crítica?". As demais perguntas desencadeadoras foram elaboradas mediante a escuta, transcrição e leitura atenta do texto transcrito a partir das sessões anteriores.

As entrevistadas são Andressa, que é psicóloga, docente e supervisora de estágio na área de Psicologia Escolar, e Sofia, que foi estagiária de Andressa no ano de 2011 (os nomes apresentados são fictícios, para preservar a identidade das entrevistadas.). A trajetória de formação e atuação profissional de Andressa é marcada por uma mudança gradativa no modo teórico-prático de compreender a Psicologia Escolar, pois a pós-graduação cursada pela entrevistada - aprimoramento, mestrado e doutorado - apresentava uma compreensão conservadora da Psicologia Escolar, baseadas em referenciais que reduziam os problemas escolares ao aluno ou à sua família. Neste período, apesar de ainda não ter conhecimento da perspectiva crítica na área, Andressa demostrava dúvidas quanto a esse posicionamento teórico-prático, observadas principalmente nas conversas com sua psicoterapeuta, que acabou se tornando posteriormente sua supervisora nos 
atendimentos às questões educacionais em clínica particular que realizava paralelamente à pós-graduação. A partir daí, Andressa começou a buscar elementos que a ajudassem a compreender a Psicologia Escolar de um modo mais ampliado.

Nos dias das sessões de entrevista, Sofia, que estava no último período do curso de Psicologia, relatou que a Psicologia Escolar não era sua área de maior interesse, mas que ter feito o estágio nesta área fora uma experiência muito importante em sua formação possibilitando a vivência de diversas aprendizagens, em que ela pôde, a partir da mediação de Andressa, das demais colegas e dos encontros propiciados nas práticas, apropriar-se de um olhar mais ampliado acerca da Psicologia Escolar.

\section{ANÁLISES}

A construção das categorias de análise seguiu o seguinte processo: a partir do objetivo da investigação, elencaram-se os principais conceitos teóricos que sustentam a pesquisa (mediação/processo de ensino-aprendizagem e formação de conceitos científicos), os quais conduziram à leitura dos dados da pesquisa, contribuindo para construir as categorias de análise que serão apresentadas a seguir.

\section{Mediação do outro nas escolhas e aprendizagens}

As participantes destacaram pessoas importantes para suas escolhas de formação profissional e demais aprendizagens que, de algum modo, contribuíram para a apropriação de um posicionamento crítico em relação à Psicologia Escolar. O curso de aprimoramento de Andressa apresentara uma concepção conservadora de Psicologia Escolar, gerando inquietações e dúvidas quanto a este modo de compreender as questões escolares, e isto era levado para a psicoterapia que fazia na época. Após o primeiro ano, interrompeu a psicoterapia e passou a realizar parcerias profissionais com a psicoterapeuta, participando de grupos de intervenções e de supervisões. Afirmou a entrevistada:

Então, acho que as supervisões da [psicoterapeuta], os questionamentos, as entradas que ela fazia, do tipo "presta atenção nessa família, nessa organização e lá nessa escola, o que essa garota tá te contando da escola?”. Então era um olhar que me fascinava.

É possível compreender que a mediação da psicoterapeuta instigou a entrevistada a perceber possibilidades mais ampliadas de entendimento sobre as questões educacionais, destacando elementos para os quais até então ela não se atentava. Disso podemos inferir que os conhecimentos e concepções estão atrelados aos encontros possíveis em um dado momento e à disponibilidade do sujeito para se apropriar de um novo saber. Assim, relacionar-se com quem ofereceu a possibilidade de diálogo foi fundamental para a mudança nas concepções de Andressa acerca da Psicologia Escolar.

A mediação do outro nas escolhas e aprendizagens também é um elemento que constitui toda a trajetória de Sofia. Sua mãe é pedagoga e já foi dona de uma escola, portanto, desde pequena já participava em tempo quase integral do cotidiano escolar, circulando pelos diversos espaços e tendo contato com o trabalho dos professores e demais funcionários. Com isto, pôde conhecer o contexto educacional de um modo mais ampliado, o que contribuiu para que a aprendizagem de uma perspectiva crítica sobre a escola fosse significativa: "Quando eu entrei na faculdade, acho que ficava um pouco isso, a lembrança da escola, da minha mãe, as possibilidades de trabalho junto à escola, as coisas que eu lembrava que poderiam ajudar".

A partir desta colocação se pode perguntar: que importância têm os conhecimentos e vivências prévias para a apropriação de uma determinada teoria? Esta é uma pergunta para a qual talvez não haja respostas definitivas neste momento, mas mesmo assim é interessante pensar que o processo de se apropriar de uma determinada teoria não é linear, mas permeado por elementos diversos, como a especificidade da história de cada sujeito, seus encontros e vivências e a própria densidade e complexidade da teoria. Desta forma, sendo o referencial teórico, em uma vertente crítica, pautado por uma concepção contra-hegemônica de homem e de mundo, é um grande desafio formar psicólogos escolares que compartilhem desse olhar (Guzzo, 2011).

As ementas das disciplinas, as leituras, avaliações e trabalhos acadêmicos são elementos de aprendizagem fundamentais, visto que a mediação pedagógica é essencial para que o conhecimento científico seja sistematizado (Vigotski, 2000; Facci, 2004); mas é importante 
considerar também as vivências cotidianas que o aluno já teve com escola e com a educação de forma geral. A trajetória de Sofia indica a importância da mediação e das vivências do sujeito, sejam elas relacionadas à escolarização ou não, para a apropriação de uma determinada concepção de homem e de mundo.

Sofia considera que o estágio marcou significativamente sua formação em Psicologia e que a relevância desta atividade se deveu principalmente ao modo como Andressa conduziu o estágio: um trabalho voltado para a formação continuada de docentes da Educação Infantil. Segundo o relato de Sofia, a professora que a acompanhou apresentava uma prática interessante e contextualizada e por isso sentiu dúvidas em relação à forma de intervir junto a ela. Em meio a estes desafios, aponta que as falas e indagações de Andressa foram muito importantes:

Aí eu chegava: "Andressa, o que eu vou dizer para a professora? Não tem o que dizer" e aí a Andressa pegou esse fiozinho: "será que ela sabe que ela está fazendo isso? Será que ela vê que ela está fazendo essas coisas?

O relato da estagiária se aproxima do conceito de zona de desenvolvimento iminente (Vigotski, 2001; Prestes, 2010), em seu pressuposto de que, com a ajuda de outra pessoa mais experiente, o sujeito é capaz de ir além de suas capacidades atuais, o que indica que a mediação cria possibilidades para o desenvolvimento. Andressa instigou Sofia a investigar e ampliar sua compreensão da prática da professora que acompanhava, contribuindo para a construção de novas possibilidades de atuação em Psicologia Escolar.

Andressa e Sofia indicaram que a aprendizagem se desenvolve como um processo social, em que o outro é parte essencial do eu (Vigotski, 2000; Pino, 2005), em uma relação que não se restringe ao contexto imediato, já que está sempre integrada a um contexto cultural mais amplo.

\section{Desafios e contradições: movimentos inerentes à apropriação de uma perspectiva crítica em Psicologia Escolar e Educacional}

Andressa se referiu à apropriação de uma visão crítica na mencionada área como um caminho construído em meio a dúvidas, rupturas e mudanças. A pós-graduação realizada em uma vertente tradicional da Psicologia Escolar suscitara-lhe inquietações diversas; na época não tinha o olhar que tem hoje sobre a Psicologia Escolar e por isso não conseguiu compreender imediatamente quão individualizante era a perspectiva teórica que sustentava suas pesquisas. Relacionou esta decisão a suas condições concretas de vida no momento, como a segurança de cursar o mestrado e o doutorado em uma instituição na qual já estava inserida, tendo inclusive o auxílio financeiro da bolsa de estudos. Afirma:

\begin{abstract}
Hoje, é difícil olhar para essa história, porque hoje, olhando para ela, essa pergunta vai no peito: "Peraí! Que história que é essa? Se você já tinha essa inquietação, vai buscar supervisão fora, vai levando isso, como é que você diz sim a esse mestrado que era uma continuação?"... Naquele momento acho que era o que eu dava conta.
\end{abstract}

Por outro lado, as incoerências presentes em sua história indicam um aspecto importante da apropriação de uma perspectiva crítica. Como o processo de aprendizagem não acontece de forma linear, mas de modo dialético (Pino, 2005), Andressa identifica neste caminho contradições inerentes à constituição humana e importantes para aprender um novo jeito de pensar, de modo que o fato de estar imersa em uma perspectiva conservadora em Psicologia Escolar não a impediu de se dar conta de que existem outras possibilidades além daquelas que estava aprendendo, o que contribuiu significativamente para ela questionar e, mais tarde, romper com aquele olhar individualizante.

A necessidade de construir novos entendimentos sobre a Psicologia Escolar impulsionou a busca por teorias que lhe possibilitassem uma compreensão mais ampla do contexto educacional. Ao participar de um processo seletivo para ingressar como docente em uma instituição de Ensino Superior, Andressa se deparou com uma bibliografia totalmente voltada para uma perspectiva crítica em Psicologia Escolar e Educacional, com a qual se identificou prontamente. Observa-se, no relato a seguir, a importância das leituras realizadas nesse momento para a apropriação de uma base teórica mais sistematizada: "ao ler o texto da Adriana [Marcondes Machado] eu fiquei assim: "gente, mas tem gente que faz o que eu gostaria 
de fazer!", e isso me inspirou muito, me fortaleceu muito".

O processo de apropriação da teoria referente às questões escolares e à atuação do psicólogo diante delas foi se tornando gradativamente mais crítico e ampliado para a participante, que passou a incorporar elementos até então apenas pressentidos como importantes para sua prática profissional. Este processo remete às formulações de Vigotski quanto aos conceitos espontâneos e conceitos científicos (Vigotski, 2000; Nascimento, 2010). Apropriar-se do modo de pensar cientificamente não é algo que ocorra mediante a repetição ou por assimilação, mas é um processo vivo, que acontece por meio dos desafios que são colocados para o sujeito e passa necessariamente pela mediação. Assim, a apropriação de uma visão crítica de Psicologia Escolar não se formou de modo intrínseco em Andressa, mas foi constituída por meio dos diferentes tipos de mediação - como supervisões com a psicoterapeuta, leituras, partilhas com colegas de trabalho e outros.

Andressa ainda apontou que em seu fazer profissional atualmente encontra desafios e que, por isso, a aprendizagem de uma perspectiva crítica se encontra em curso contínuo: "Porque acho que a resposta é: eu continuo aprendendo. Ainda não dá para usar isso no passado, isso está acontecendo". Sua fala demonstra que o conhecimento de uma teoria não é algo que se armazene estaticamente, mas um saber que é constituído no plano social e está em constante mudança. Além disto, indicou que sua prática docente constitui-se como uma constante busca por aprender, o que remete à importância da formação continuada para a práxis profissional (Facci, 2004; Silva, 2010).

Entre os desafios enfrentados ao longo de sua formação como psicóloga escolar, Sofia destaca as duas disciplinas desta área que continham uma parte prática como vivências difíceis. Para ela, o insucesso nas práticas deveu-se tanto ao pouco tempo disponibilizado pelas disciplinas quanto à falta de experiência dela e de seus colegas, que pela primeira vez atuavam como psicólogos escolares. Ela se questionava e refletia:

Por que deu errado la prática desenvolvida na disciplina]? Por que as atividades não tinham liga? Algumas tinham, algumas das crianças se envolviam, mas grande parte não. Por quê? Porque não foram novamente ouvidas essas crianças. A gente não ouviu da voz delas... Embora a gente tenha tentado um pouco também. Acho que a gente ainda estava caminhando, né?

Sendo assim, a apropriação teórico-prática de Sofia consistiu em um processo gradual, em que as vivências, ainda que permeadas de dificuldades, demonstraram-se fundamentais para suscitar reflexões acerca dos pressupostos teóricos, indicando a unidade dialética entre as instâncias teoria e prática. A esse respeito, Cury (2011) salienta a importância de que a universidade de fato cumpra seu papel humanizador, propiciando aos alunos uma formação integral. Para isto, os conteúdos devem ir além do mero ensino mecanicista e abarcar uma significação humana e social, sendo fundamental, para isto, unir teoria e prática.

O trabalho desenvolvido com a professora de Educação Infantil durante o estágio de Sofia foi um desafio fundamental para sua trajetória, uma vez que esta docente já apresentava um trabalho interessante. Sofia aceitou com coragem esta proposta e contou que ao final recebeu da professora uma devolutiva importante sobre o trabalho realizado: "ela me traz depois esse feedback: 'Nossa, nunca tinha parado pra pensar por que que eu escolhi pedagogia e por que eu escolhi educação infantil'. E aí essas perguntas foram frutificando e melhorando ainda mais o cotidiano dela."

As situações relatadas pelas participantes vão ao encontro da afirmação vigotskiana, permitindo pensar que a aprendizagem de um determinado conceito científico não se concretiza de forma imediata, mas mediante um processo que se desenvolve de acordo com as necessidades e desafios encontrados pelo sujeito em seu contexto.

Nesse sentido, cabe um destaque sobre as atividades proporcionadas ao estudante de Psicologia no que se refere à aprendizagem da profissão. Guzzo (2011) considera que formar psicólogos no Brasil tem sido um grande desafio, principalmente em decorrência do sucateamento dos cursos de graduação, que, salvo exceções, não têm conseguido formar profissionais de fato preparados para lidar com a realidade do país. Apesar deste panorama, é válido destacar atividades que são fundamentais para uma 
formação consistente, entre elas o estágio supervisionado (Pires, 2011).

São fundamentais os desafios atrelados ao fazer profissional, seja no estágio seja nos demais momentos da trajetória do sujeito em sua profissão, pois constantemente instigam novos entendimentos e práticas mais elaboradas.

\section{Atividade prática como possibilidade de apropriação teórica}

Os excertos das entrevistas mostrados a seguir indicam que a prática é um componente fundamental para a aprendizagem: "Eu acho que são muito importantes os conceitos que os autores trazem, mas eu me importo mais em assimilar isso e ver isso na prática funcionando" (Sofia); "É... e aí o meu desafio era pensar: como é que eu posso ensinar isso [Psicologia Escolar crítica], sendo coerente com isso? Tendo uma prática coerente com isso?"(Andressa).

Isto instiga a pensar: por que a prática é tão importante para quem está se apropriando de uma profissão? Afinal, o que as depoentes chamam de "prática"? A simples presença física em alguma instituição ou estar diante de um cliente é o bastante? De fato, é fundamental que o futuro psicólogo escolar possa vivenciar o contexto educacional, pois, ao conhecer essa dimensão específica de sua área de atuação, o estagiário poderá questioná-la e pensar em possibilidades de intervenção (Guzzo, Costa \& Sant'Ana, 2009). Por outro lado, não se pode considerar que o fato de estar imerso na realidade escolar seja suficiente, muito menos negligenciar a importância da dimensão teórica para a apropriação do fazer profissional.

Cabe fazer aqui uma observação sobre a articulação entre a teoria e a prática na formação de psicólogos e de outros profissionais, uma vez que muitos currículos tendem a separar a formação teórica da formação prática em nome da chamada "racionalidade técnica" (Schön, 2000). O Currículo Mínimo do curso de Psicologia previa uma formação em que o estudante primeiramente cursasse todas as disciplinas e somente ao final realizasse os estágios profissionalizantes. Com o advento das "Novas Diretrizes Curriculares para os Cursos de Psicologia", fixadas pelo Parecer 0062/2004 (CNE, 2004), verifica-se uma articulação mais próxima entre teoria e prática, uma vez que o documento estabelece que os estágios sejam feitos ao longo do curso (Cruces, 2009). Este dispositivo indica tentativas de aliar a prática à teoria desde o início da formação dos alunos, no sentido de romper com a separação entre estas duas importantes instâncias do conhecimento.

Sobre esta questão, cabe destacar que Sofia trouxe as dimensões da teoria e da prática de modo oscilante, demonstrando ora cisão, ora unidade entre os dois campos. Quando discorreu sobre o modo como prefere aprender o fazer profissional, afirmando preferir a dimensão da atuação, a entrevistada demonstrou uma maior valorização da prática do que da teoria; por outro lado, ao falar sobre as disciplinas da área de Psicologia Escolar, demonstrou valorizar mais a teoria do que a prática, ao se queixar do pouco tempo destinado a leituras aprofundadas e à aprendizagem dos conceitos.

Sofia demonstrou ter desenvolvido no estágio uma prática interessante e coerente com uma proposta crítica em Psicologia Escolar, buscando compreender o contexto de atuação a partir de suas múltiplas determinações e complexidades e atuando de modo a contribuir de fato com a qualidade das relações na escola. Ao mesmo tempo ela afirmou: "Não sei se eu sei os conceitos, né, da teoria [da Psicologia Escolar e Educacional crítica]" Esta aparente contradição, de não saber ao certo se realmente conhecia os conceitos e ao mesmo tempo desenvolver uma prática coerente com este referencial, parece indicar que o aspecto teórico está tão dialeticamente embutido na atuação da estagiária que ela não se dá conta de que aquela ação prática está plena de teoria. Muitas vezes o estagiário não percebe que é necessário a teoria estar internalizada para que esta possa se espraiar em suas práticas; entretanto, mesmo que o estagiário não transite ainda com fluência por um determinado conhecimento teórico, o contato com este já provoca questionamentos que modificam suas ações na prática.

Esta compreensão abrangente acerca da importância da dimensão da prática também se faz presente na fala de Andressa. A mudança de uma perspectiva teórica conservadora para um olhar crítico em Psicologia Escolar foi desencadeada pela atividade prática desenvolvida nos atendimentos, atrelada à mediação de sua psicoterapeuta. Nesse primeiro momento Andressa relatou que ainda não havia se deparado com a literatura relativa à Psicologia Escolar e Educacional crítica, com a qual veio a estabelecer contato quando participou do processo seletivo para professora universitária; mas esta mudança inicial já Ihe 
trouxe elementos importantes de uma concepção crítica, como, por exemplo, considerar a queixa escolar em suas múltiplas determinações, incluindo um trabalho coletivo, do qual possam participar a família e a escola e que parece ter sido fundamental para que ela se identificasse com a posterior leitura dos textos relativos à Psicologia Escolar numa perspectiva contextualizada.

Em sua atividade docente, Andressa demonstrou compreender a prática como uma possibilidade de estar constantemente refletindo sobre sua atuação profissional e apropriando-se da teoria, pois o conhecimento teórico é entendido como um processo não estanque, mas vivo e dinâmico, constituído no diálogo com a prática. É o que nos contou sobre sua conduta como professora, na busca por uma proposta de ensinoaprendizagem orientada pela Teoria HistóricoCultural: "E uma prática mais coerente envolvia desenvolver uma prática que vai na contramão do sistema. Então, contra provas, contra chamadas, contra decorebas, contra aulas expositivas...."

Observa-se nos relatos das participantes que a apropriação de uma concepção crítica não se deu mediante uma transposição direta da teoria para a realidade, e sim, em decorrência de um processo no qual as leituras foram sustentando os questionamentos que emergiam da prática. Neste sentido, o processo vivenciado por Andressa vai ao encontro da seguinte afirmação de Tanamachi (1997):

Não é da teoria que se extrai a ação, mas é a importância da ação no interior de uma determinada realidade que permite integrar e adequar os instrumentos elaborados por diferentes correntes teóricas (que expressam e contêm as concepções teóricas que os fizeram surgir) aos propósitos e finalidades de apreensão/explicação dos fenômenos da realidade. (p. 136)

A prática que as participantes sinalizaram como importante é aquela mediada pelos elementos teóricos com a colaboração de professores e pares, o que lhes possibilita apreender a realidade educacional a partir de uma perspectiva mais fundamentada.

\section{Estudos teóricos como possibilidade de apropriação conceitual e prática}

Esta categoria destaca os estudos teóricos como um componente fundamental para a apropriação dos elementos teórico-práticos de uma perspectiva crítica em Psicologia Escolar por parte das entrevistadas. Andressa enfatizou o encontro com a literatura crítica em Psicologia Escolar como um momento importante para a mudança de uma concepção conservadora para um entendimento crítico. Ao estudar a bibliografia indicada no processo seletivo para docente, percebeu sua identificação com a teoria: "O primeiro que eu li foi Práticas críticas [Meira \& Antunes, 2003a]. Eu li o livro três vezes.... Porque era como se o mundo tivesse aberto, um mundo, uma janela, uma megajanela".

Antes de se deparar com as leituras em uma perspectiva crítica em Psicologia Escolar, Andressa já se encontrava em um movimento de ruptura com a visão conservadora que adotara até então e sua fala remete ao processo de formação de conceitos científicos postulado por Vigotski (2000). Na concepção do autor, como explica Facci (2004), enquanto os conceitos espontâneos são constituídos mediante as vivências e a apreensão direta da realidade, os científicos são desenvolvidos pela sistematização do conhecimento, por meio do ensino; mas estas instâncias não devem ser compreendidas de modo cindido, pois "os conceitos espontâneos constituem a base dos conceitos científicos" (Facci, 2004, p. 224) portanto estão dialeticamente relacionados.

Andressa relatou inquietação com uma perspectiva conservadora em Psicologia Escolar já na especialização, embora ainda de modo incipiente. Quando teve contato com um conjunto de saberes sistematizados, o incômodo que tinha como intuitivo toma outra dimensão. A partir das mediações em sua aprendizagem e da apropriação de saberes sistematizados, seu conhecimento prévio e seus questionamentos foram se modificando, tornando possível a aprendizagem dos elementos teórico-práticos da Psicologia Escolar crítica.

Sofia também identificou o estudo teórico como parte fundamental de sua trajetória na Psicologia Escolar e revela que, embora considere não ter se apropriado profundamente dos conceitos teóricos, as disciplinas cursadas nesta área foram muito importantes para instigála a pensar sobre as questões educacionais de um modo mais contextualizado, de modo a contribuírem até mesmo para que depois escolhesse o estágio na área. Ela disse: "a partir das disciplinas isso foi se ampliando, foi 
mostrando os outros sujeitos que estavam envolvidos, como que as outras questões históricas, culturais daquele mesmo sujeito influenciavam no surgimento daquela queixa [escolar]....".

Embora tenha adquirido uma compreensão mais abrangente por meio das disciplinas cursadas, foi no momento do estágio que Sofia identificou uma apropriação mais efetiva da teoria: "Então, a partir do estágio é que eu fui realmente entendendo os conceitos e podendo ver eles na prática; e isso tudo associado à minha trajetória....".

Ambas as participantes entendem os estudos teóricos como essenciais para a formação profissional, uma vez que a literatura tem a função de atualizar o conhecimento, possibilitando 0 acesso às mais recentes pesquisas realizadas nas diversas áreas de atuação. Para Patto (2005), atualmente a fragilidade do estudo teórico é um forte componente da inconsistência na formação dos profissionais em Psicologia, pois estudar a teoria não é apenas buscar técnicas para resolver problemas imediatos, mas dedicar-se ao conhecimento da ciência como um todo. Andressa considerou a realização contínua de estudos teóricos no campo da Psicologia Escolar e dos processos de ensino-aprendizagem como um exercício que, além de possibilitar a aprendizagem conceitual, permitiu-lhe a apropriação de uma prática mais coerente com os pressupostos teóricos estudados: " $E$ aí a minha relação com a teoria de Vigotski já é uma teoria que já não é mais uma teoria cerceada ou circunscrita à sala de aula". Sofia também reconheceu a importância do estudo da teoria, principalmente quando associado à pratica: "Então não tinha um momento de grupo de estudo e um momento de discussão da prática, era tudo muito junto".

Para as entrevistadas, a apropriação teórica dos elementos críticos em Psicologia Escolar é um processo dialeticamente atrelado à prática. Assim, os estudos teóricos destacam-se como fundamentais para uma compreensão mais ampliada do fazer profissional e da área de conhecimento da Psicologia Escolar e Educacional como um todo, indicando que a apropriação da teoria ultrapassa o pragmatismo da mera resolução de problemas e de fato modifica o modo de agir do sujeito no mundo (Vigotski, 2000; Nascimento, 2010).
São vários os fatores que contribuem para o processo de apropriação conceitual, de forma que o simples cumprimento da grade curricular, o chamado ensino escolar, não é suficiente para o aprendizado do aluno (Andrade e Silva, 2009); porém, em se tratando de um saber científico e da aprendizagem de uma profissão, torna-se imprescindível o ensino escolar, que abarca necessariamente $\mathrm{o}$ estudo do conhecimento historicamente produzido (Vigotski, 2000; Facci, 2004; Nascimento, 2010).

\section{A confluência das trajetórias de Andressa e Sofia: possibilidades do estágio supervisionado para a apropriação de uma perspectiva crítica em Psicologia Escolar e Educacional}

Neste estudo o estágio se configura como uma categoria central de análise, pois é o cenário em que as entrevistadas compartilham um espaço pleno de elementos que compõem o processo de ensino-aprendizagem de uma perspectiva crítica em Psicologia Escolar e Educacional. Observemos a trecho de Sofia a seguir: "essa experiência do estágio em psicologia escolar, ela não foi qualquer experiência, ela muda mesmo o meu jeito de ver, de pensar mesmo a psicologia em si, a inserção desse psicólogo também nesse contexto".

Para a participante, o estágio em Psicologia Escolar contribuiu para sua formação como psicóloga, independentemente do contexto em que vá trabalhar. A aprendizagem propiciada por este estágio se deve a diversos fatores, entre eles a sua organização pedagógica. Sofia contou que nas primeiras supervisões, ao invés de apresentar um roteiro preestabelecido de atividades, Andressa propôs uma construção conjunta do plano de trabalho, contando, inclusive, com uma sondagem a respeito das habilidades e preferências de cada estagiária, cujo objetivo era que cada aluna identificasse tais características, a fim de valer-se delas posteriormente no decorrer do estágio. Sofia destacou, ainda, a valorização do grupo pela supervisora e a participação conjunta das estagiárias nas discussões teórico-práticas.

Aqui é possível pensar na relação ensinoaprendizagem proposta por Vigotski (2007) por meio do conceito de zona de desenvolvimento iminente, segundo o qual, com a ajuda de um adulto mais experiente ou dos pares, o sujeito é capaz de ir além daquilo que consegue fazer sozinho. Assim, o trabalho em grupo, que permite o diálogo e a partilha de vivências, foi 
um elemento importante para enriquecer o processo de aprendizagem de Sofia, impulsionando-a a um posicionamento crítico em Psicologia Escolar.

Outra característica do estágio, valorizada tanto pela supervisora quanto pela estagiária, é o fortalecimento de uma base teórica que acompanha a prática, por meio de leituras intensas seguidas de discussões. Andressa considerou o estudo da teoria como fundamental para instigar 0 aluno a desenvolver uma compressão questionadora e um posicionamento crítico em Psicologia Escolar, embora muitas vezes sinta dificuldade em mediar esta atividade junto aos alunos, que por vezes chegam ao estágio sem o hábito de ler com os textos com espírito crítico.

Esse movimento dialético na fala das entrevistadas, em que os estudos teóricos aparecem, ao mesmo tempo, como algo fundamental e árduo, convida a refletir sobre como a teoria tem comparecido na graduação. Chauí (2001) tece uma crítica ao modelo de universidade atual, construído sobre os alicerces neoliberais, e ressalta que uma das graves consequências disto na realidade brasileira é o sucateamento da graduação, que resulta muitas vezes em um número elevado de horas-aula e uma ausência de aporte bibliográfico e, consequentemente, em uma formação rápida e de má qualidade. Nesse sentido, cabe ressaltar a importância do conhecimento científico aprendido por meio do processo de escolarização (Facci, 2004), uma vez que a escola, apresentando o conhecimento historicamente produzido de forma organizada e sistematizada, possibilita a humanização do sujeito.

Assim se observa no estágio de Andressa uma tentativa de romper com esta lógica, valorizando o estudo da teoria como atividade fundamental, pautada por uma leitura crítica e reflexiva, estabelecendo um diálogo com a prática. Além disso, Andressa ressaltou a supervisão como momento precioso para a aprendizagem dos estagiários, em que juntamente com os elementos teóricos são realizados questionamentos a respeito das ações no estágio que possibilitam ao aluno desenvolver uma compreensão sobre a própria prática, constituindo elementos importantes da mediação pedagógica (Vigotski, 2000; Facci, 2004) realizada pela supervisora na condução do estágio em Psicologia Escolar.
No que se refere à formação dos estagiários em uma perspectiva ampliada e interdisciplinar, Sofia aponta que Andressa valorizou a arte como um importante elemento para a formação profissional. Andressa também destacou este mesmo elemento: "... tem uma outra ferramenta que é a arte... à medida que eu vejo o quanto ela é transformadora em mim, o que ela tem provocado em mim, eu tento levar isso para eles também".

Isto mostra um ensino não tecnicista, que transcende o mero treinamento, orientando-se por uma perspectiva humanizadora e integral, o que vai ao encontro da reflexão de Patto (2007), que critica a formação mercadológica que muitos cursos de Psicologia oferecem atualmente e considera que é importante enriquecer a aprendizagem dos alunos com as contribuições das diversas áreas das ciências humanas.

A modalidade de atuação apresentada por Andressa e Sofia leva a refletir sobre as possibilidades de trabalho do psicólogo escolar, pois as atribuições deste profissional ainda se configuram como uma discussão contemporânea (Martínez, 2010). Além da frequente visão do psicólogo escolar como aquele que realiza somente atendimentos individuais e em caráter clínico, não raro verifica-se que este também é desvalorizado no contexto educacional em decorrência da representação errônea que muitas vezes se tem de que o psicólogo seria incapaz de resolver as questões referentes ao contexto educacional (Martínez, 2010). A supervisora afirmou:

A minha intenção no estágio é provocar isso, as possibilidades, inúmeras possibilidades que a gente tem e que não dependem da técnica, e que o maior instrumento realmente é você ... como você olha pra aquilo, como você organiza sua ação. Então, a partir disso, eu gostaria que eles conseguissem ver as possibilidades que eu vejo.

Andressa demonstrou compreender a necessidade de instigar os estagiários a compreenderem um posicionamento crítico, desconstruindo uma postura conservadora em Psicologia Escolar e ao mesmo tempo construindo as alternativas possíveis. Tendo em vista que uma concepção crítica significa não apenas negar determinados conceitos, mas principalmente investigar a raiz histórica que os originou, para propor novos significados e ações 
(Patto, 1984), Ao se dedicarem a um trabalho que valoriza o professor, respeitando seu saber e ampliando suas possibilidades em sala de aula, Andressa e Sofia indicam caminhos interessantes para a atuação e formação do psicólogo escolar. É o que se observa no relato de Sofia: "então a gente não vai apontar o que foi problemático somente, ... o foco no recurso também: 'Olha que bacana você fez! Você viu você fazendo isso? Você sabe que faz isso, nessa situação?". Este trecho remete à reflexão abaixo, de Tanamachi e Meira (2003), sobre a importância de ações que contribuam para a emancipação humana:

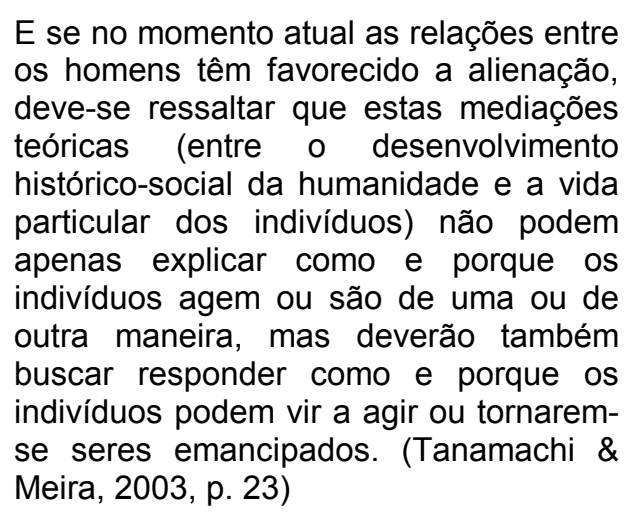

Por meio destas discussões foi possível constatar a importância do estágio para a formação do futuro psicólogo escolar e entender que, para que o estagiário de fato se aproprie de uma compreensão crítica da teoria e da prática, é fundamental que as ações desenvolvidas no estágio sejam cuidadosamente planejadas. Para isto se torna imprescindível a figura do supervisor (Pires, 2011; Cury, 2011) como aquele que medeia junto aos estagiários os conceitos teóricos, entrelaçando-os às vivências práticas.

\section{CONSIDERAÇÕES FINAIS}

Este artigo apresentou uma investigação sobre o processo de apropriação de uma perspectiva crítica em Psicologia Escolar e Educacional por uma supervisora e uma estagiária. As análises indicam que a mediação do outro na trajetória das participantes de fato suscitou profundas mudanças no modo de compreender a Psicologia Escolar, demonstrando que a aprendizagem de conceitos é constituída intrinsecamente a partir do plano social (Vigotski, 2000). Além disso, as entrevistadas indicaram que a apropriação de uma perspectiva teórica constitui-se como um processo vivo, dinâmico e continuamente em curso (Vigotski, 2000; Nascimento, 2010).

A atividade prática e os estudos teóricos sobressaíram como componentes indispensáveis para a apropriação conceitual, sendo indicada pelas análises a necessidade de compreender a unidade dialética de teoria e prática, sendo a apropriação de conceitos científicos dependente do conhecimento escolar pedagogicamente organizado (Vigotski, 2000; Facci, 2004). Ainda assim, o depoimento das participantes indica que as vivências fora do contexto da escolarização formal são muito importantes neste processo.

O estágio supervisionado destacou-se como atividade essencial para a apropriação de uma perspectiva crítica em Psicologia Escolar, revelando que a mediação supervisor-estagiários e grupo de estagiários foi fundamental para a estagiária se apropriar da teoria e prática de uma perspectiva crítica em Psicologia Escolar e mostrando a importância das ações pedagógicas da supervisora neste processo.

Diante das análises desenvolvidas, é importante considerar como pensar em uma formação para o psicólogo escolar que abarque o ensino e aprendizagem de uma perspectiva crítica. Os professores dos cursos de graduação, os supervisores de estágio profissionalizante e os próprios estagiários têm importante lugar nesta discussão, assim como as políticas públicas relativas ao Ensino Superior, na busca por um trabalho coletivo que, ao incorporar os avanços da Psicologia Escolar e Educacional, possa concretizar esta formação de modo cientificamente respaldado e social e eticamente comprometido. Por fim, vale ressaltar a importância de que, a partir deste trabalho, novas reflexões e estudos possam dar continuidade à trajetória trilhada até o momento.

\section{REFERÊNCIAS}

Andrade e Silva, P. S. (2009). Memórias de formação do curso de psicologia: elementos para uma análise crítica. Tese de Doutorado, Faculdade de Educação, Universidade Estadual de Campinas, Campinas, SP.

Barbosa, D. R., \& Souza, M. P. R. (2012). Psicologia educacional ou escolar? Eis a questão. Revista Semestral da Associação Brasileira de Psicologia Escolar e Educacional, 16(1), 163-173. Recuperado em 19 de novembro de 2012, de 
http://www.scielo.br/scielo.php?pid=S141385572012000100018\&script=sci_arttext

Chauí, M. (2001) Escritos sobre a universidade. São Paulo: UNESP.

Cruces, A. V. (2006). Egressos de cursos de psicologia: preferências, especializações, oportunidades de trabalho e atuação na área educacional. Tese de Doutorado, Universidade de São Paulo, São Paulo.

Cruces, A. V. (2009). Desafios e perspectivas para a psicologia escolar com a implantação das diretrizes curriculares. In C. M. M. Araujo, Psicologia escolar: novos contextos de pesquisa, formação e prática (pp. 15-34). Campinas, SP: Alínea.

Cury, D. G. (2011). A relação entre professor e aluno no Ensino Superior vista por meio da reprovação. Dissertação de Mestrado, Instituto de Psicologia, Universidade Federal de Uberlândia.

Facci, M. G. D. (2004) Valorização ou esvaziamento do trabalho do professor?: um estudo críticocomparativo da teoria do professor reflexivo, do construtivismo e da psicologia vigotskiana. Campinas, SP: Autores Associados.

Guzzo, R. S. L. (2011) Desafios cotidianos em contextos educativos: a difícil formação de psicólogos para a realidade brasileira. In R. G. Azzi, \& M. H. T. A. Gianfaldoni (Orgs.), Psicologia e educação (pp. 253-270). São Paulo: Casa do Psicólogo.

Guzzo, R. S. L., Costa, A. S., \& Sant'Ana, I. M. (2009). Formando Psicólogos escolares: problemas, vulnerabilidades, desafios e horizontes. In C. M. M. Araujo (Org.), Psicologia escolar: novos cenários e contextos de pesquisa, formação e prática (pp. 35-52). Campinas: Alínea.

Meira, M. E. M. (2012). A crítica da Psicologia e a tarefa crítica na Psicologia. Psicologia Política, 12(23). Recuperado em 04 de dezembro de 2013, de

<http://pepsic.bvsalud.org/scielo.php?pid=S15195 49X2012000100002\&script $=$ sci_arttext $>$

Marinho-Araujo, C. M. M., \& Almeida, S. F. C. (2008). Psicologia escolar: construção e consolidação profissional. Campinas, SP: Alínea.

Martins, L. M. (2006). As aparências enganam: divergências entre $o$ materialismo histórico dialético $e$ as abordagens qualitativas de pesquisa. Trabalho apresentado na $29^{a}$ Reunião Anual da ANPED. Recuperado em 20 de setembro de 2011, de http://www.anped.org.br/reunioes/ 29ra/ trabalhos/trabalho/GT17-2042--Int.pdf

Martínez, A. M. (2010) O que pode fazer o psicólogo na escola? Revista Em Aberto, 23(83), 39-56. Recuperado em 16 de maio de 2011, de http://www.rbep.inep.gov.br/index.php/ emaberto/article/viewFile/1634/1298

Meihy, J. C. B. (2002). Manual de história oral. São Paulo: Loyola.

Ministério da Educação. Conselho Nacional de Educação/Câmara de Educação Superior (2004).
Parecer 0062/2004, aprovado em 19/02/2004, fixa as Diretrizes Curriculares Nacionais para os cursos de graduação em Psicologia. MEC: Brasília, DF.

Nascimento, C. P. (2010). A organização do ensino e a formação do pensamento estético-artístico na teoria histórico-cultural. Dissertação de Mestrado, Faculdade de Educação, Universidade de São Paulo, São Paulo.

Patto, M. H. S. (1984). Psicologia e ideologia: uma introdução crítica à psicologia escolar. São Paulo: T. A. Queiroz.

Patto, M. H. S. (2005). Exercícios de indignação: escritos de educação e psicologia. São Paulo: Casa do Psicólogo.

Patto, M. H. S. (2007). A psicologia em questão. In M. H. S. Patto, \& J. Frayze-Pereira (Orgs.), Pensamento cruel - humanidades e ciências humanas: há lugar para a psicologia? (pp. 3-16). São Paulo: Casa do Psicólogo.

Pino, A. (2005). As marcas do humano: as origens da constituição cultural da criança na perspectiva de Lev S. Vigotski. São Paulo: Cortez.

Pires, V. S. (2011). O processo de subjetivação profissional durante os estágios profissionalizantes em psicologia. Dissertação de Mestrado, Instituto de Psicologia, Universidade Federal de Uberlândia, Uberlândia, MG.

Prestes, Z. (2010). Quando não é quase a mesma coisa: análise de traduções de Lev Semionovitch Vigotski no campo educacional. Tese de Doutorado, Faculdade de Educação, Universidade de Brasília, Brasília.

Schön, D. A. (2000). Educando o profissional reflexivo: um novo design para o ensino e a aprendizagem (R. C. Costa, trad.). Porto Alegre: Artmed.

Silva, S. M. C. (Org.). (2010). A atuação do psicólogo na rede pública de educação frente à demanda escolar: concepções, práticas e inovações. Relatório de Pesquisa, Instituto de Psicologia, Universidade Federal de Uberlândia, Uberlândia, MG.

Souza, M. P. R. (2009). Psicologia escolar e educacional em busca de novas perspectivas. Revista Semestral da Associação Brasileira de Psicologia Escolar e Educacional, 13(1), 179-182. Recuperado em 15 maio, 2011, de http://www.scielo.br/scielo.php?pid= S141385572009000100021\&script=sci_arttext

Tanamachi, E. R. (1997). Visão crítica de educação e de psicologia: elementos para a construção de uma visão crítica de psicologia escolar. Tese de Doutorado, Universidade Estadual de São Paulo, Marília.

Tanamachi, E. R., \& Meira, M. E. M. (2003). A atuação do psicólogo como expressão do pensamento crítico em Psicologia da Educação. In M. E. M.Meira, \& M. A. M. Antunes, Psicologia escolar: práticas críticas (pp. 11-62). São Paulo: Casa do Psicólogo. 
Vigotski, L. S. (2000). A construção do pensamento e da linguagem. São Paulo: Martins Fontes.

Vigotskii, L. S. (2001). Aprendizagem e desenvolvimento na idade escolar. In L. S. Vigotskii, A. R. Luria, \& A. N. Leontiev, Linguagem, desenvolvimento e aprendizagem (pp. 103-117). São Paulo: Ícone.

Vigotskii, L. S. (2007). Psicologia pedagógica: edição comentada. Porto Alegre: Artmed.

Fabiana Marques Barbosa Nasciutti: mestre em Psicologia pela Universidade Federal de Uberlândia, doutoranda em Educação pela Universidade Estadual de Campinas.

Silvia Maria Cintra da Silva: professora do Instituto de Psicologia da Universidade Federal de Uberlândia. 